\title{
A Study of Percutaneous Antegrade Transvesical Fulguration of Posterior Urethral Valves in Neonates and Infants
}

\author{
Authors \\ Dr Khwaja Nasim Ahmad', Dr Ashutosh Patel ${ }^{2}$, Dr Md. Abdur Rahman', \\ Dr Yasir Tajdar ${ }^{4}$ \\ ${ }^{1}$ Associate Professor, Dept. of General Surgery, K.M.C. Katihar \\ ${ }^{2}$ Assistant Professor, Dept. of General Surgery, K.M.C. Katihar \\ ${ }^{3,4}$ PGT, Dept. of General Surgery, K.M.C. Katihar \\ Corresponding Author \\ Dr Ashutosh Patel \\ Assistant Professor, Dept. of General Surgery, K.M.C. Katihar, India
}

\begin{abstract}
Due to advancement in imaging technology especially ultrasound and routine antenatal monitoring of foetus by ultrasound it has become easier to diagnose posterior urethral valve earliest possible, even can be diagnosed in utero. So earliest decompression of the kidneys and fulguration of PUV with better outcome is possible now.
\end{abstract}

\section{Materials and Methods}

This retrospective study was conducted at Katihar Medical College, Katihar in Department of General Surgery from 2015 to 2018. Total 25 patients were selceted who presented with - (i) Drribbling of urine (ii) Distentded bladder (iii) Bilateral hydronephrosis on USG (iv) Weak urinary stream.

All the cases done under general anaesthesia with muscle relaxant and infant feeding tube of $6 \mathrm{Fr}$ was passed per urethra after all antiseptic precautions. Bladder was fully distended with normal saline then the feeding tube was clamped.

With the help of large cutting needle and linen thread the lower anterior abdominal wall and anterior wall of urinary bladder was fixed by taking two deep bites $2 \mathrm{~cm}$ apart in the midline at the upper portion of the bladder including the anterior abdominal wall.

Now with the help of no. 11 blade small incision was made over anterior abdominal wall between two sutures. Now with the help of Trocar we puncture into the bladder. Through this rent we passed 17 Fr cystoscope and examined interior of the bladder and locate the per urethral feeding tube. Using infant feeding tube as a guide, bladder neck was located, now it was easier to enter into posterio urethra as it was widely dilated in case of PUV. Posterior urethral valve identified and with the help of 4 Fr ureteric catherter and metallic 
stealate the posterior urethral valve was fulgurated under vision by insulating the metallic tip ureteric catherter between the infant feeding tube and during fulguration we go on extending the metallic tip laterally so it open the urethra.

The completeness of fulguration was judged on the operating table by removing the infant feeding tube from urethra and seeing the flow of urine by pressing the bladder. No stitches were taken over anterior abdominal wall or the bladder.

Foley's catheter was inserted according to the size of urethra and remains there as needed according to the condition of the patients.

\section{Merits and Demerits}

As most of the patients were neonates and infants and at that moment we didn't have such small endoscope by which perurethral fulguration of PUV could be possible. As it is the well established facts mentioned all over the literature that there is a very high percentage of urethral stricture even $>30 \%$ in children when the existing urethroscope are used to fulguration retrogradely (through urethra).

As there was wide dilatation of posterior urethra in case of PUV, we took advantage of this situation and even there was no difficulty in entering the urethra antegradely even with $17 \mathrm{Fr}$ cystoscope and does not touches at all the wall of urethra. So there was no question of stretching or trauma to the urethra and valve can be easily fulgurated and therefore there were very much less chance of stricture of urethra in this procedure. No sophisticated, expensive and miniature instruments were required but the basic instruments can be used to fulgurate the valve and there by reducing the cost of the procedure.

Localization of the valve is very much easier in case of PUV in antegrade method of fulguration.

Only demerit of this procedure was the abdominal puncture of the bladder suprpubically and sometimes extravassation of urine can be seen.

\section{Result}

Most of the patients with posterior urethral valves improved without any complication after Percutaneous Antegrade Transvesical Fulguration, reoperation in 2 patients $(8 \%)$ is due to under fulguration to avoid any stricture urethra and death in 1 patient (4\%) due to pulmonary hypoplasia and septicemia.

\section{Discussion}

PUV is a congenital disease and with the use of different imaging modalities it can be diagnosed early in life and even antenatally. In our study 2 patients $(8 \%)$ were diagnosed antenatally. This observation was in accordance with Casale et al. (1990) according to him posterior urethral valve accounts for $10 \%$ of all infants born with significant uropathies diagnosed antenatally.

In present series $44 \%$ of patients presented in first month of life. A.N. Gangopodhyay (2003) noted that nearly half of the patients presented in first three months of life. In our series it was $64 \%$.

The incidence of posterior urethral valve in our series was 9.3 patients per year, higher in accordance with Bueschen et al. (1973), who recorded 4.2 cases per year. However, this observation was in accordance with William et al. (1965) was noted 8 cases per year.

Voiding cystourethrography was used to established the diagnosis of PUV which $100 \%$ sensitive in detecting PUV and showing vesicoureteric reflux. This study simulates with the report of A.N. Gangapodhyay (2003) who also used voiding cystourethrography as the role mode of confirmatory test and to know the reflux or any bladder abnormalities.

In our series of study we performed "Percutaneous Antegrade Transvesical Fulguration of PUV" in 20 patients $(80 \%)$ without prior diversion, rest of 5 patients having severely deranged renal parameters and early valve ablation was not possible, we went for urinary diversion (vesicotomy in 4 and percutaneous ureterostomy in 1) and delayed antegrade transvesical valve ablation through performed tract after improvement of renal function. 
In our approach to the PUV, percutaneous antegrade transvesical fulguration, there was $0 \%$ stricture even in new born and infants with small urethral calibre.

\begin{tabular}{|l|c|c|c|}
\hline \multicolumn{5}{|l|}{ Stricture of Urethra Following Treatment } \\
\hline The Series & Year & In all age & In Infants \\
\hline Myer's and Walker & 1981 & $25 \%$ & $50 \%$ \\
\hline Crooks et al. & 1982 & $8 \%$ & - \\
\hline B. Churchill et al. & 1983 & $12 \%$ & - \\
\hline Bruce et al. & 1987 & $25 \%$ & - \\
\hline Lat et al. & 1999 & $3.6 \%$ & - \\
\hline MN Uddin et al. & 2010 & $2.08 \%$ & - \\
\hline Our series & 2018 & $0 \%$ & $0 \%$ \\
\hline
\end{tabular}

\section{Conclusion}

Percutaneous Antegrade Transvesical Fulguration of posterior urethral valve is ideal route of posterior urethral valves in neonates and infants and even in children were not special expensive instrument is required rather than the simple urethrocystoscope, making the procedure least expensive and with minimal stricture formation.

\section{Bibliography}

1. Close, CE; Carr, MC; Burns, MW, Mitchell, ME.: Lower Urinary Tract changes after early valve ablation in neonates and infants: is early diversion warranted? J. Urology , 1997Mr. ; 157 (3) : 984-88. J. Urology, 1997 Mar; 157(3) :996-97.

2. Close, CE; Mitchell, ME: Posterior Urethral valves : a change of concept. Arch Esp. Urology.1998 Jul-Aug; 51(6):581-87.

3. Farhat W; McLorie G; Caplicchio G; Khoury A; Bagli,D; Merguerian, PA: Outcomes of primary valve ablation versus urinary tract diversion in patients with posterior urethral valves. Urology,2000 Oct. 1;56(4) : 653-57. 